\title{
Myxomycetes ocorrentes em áreas de caatinga e brejo de altitude no sertão de Pernambuco, Brasil
}

\author{
Nylber Augusto da Silva ${ }^{1}$ e Laise de Holanda Cavalcanti ${ }^{2,3}$
}

Recebido em 25/04/2012. Aceito em 18/07/2012

\begin{abstract}
RESUMO
(Myxomycetes ocorrentes em áreas de caatinga e brejo de altitude no sertão de Pernambuco, Brasil). O bioma Caatinga, localizado na região semiárida brasileira, está distribuído em nove estados, incluindo Pernambuco. Os objetivos deste estudo foram: obter informações que contribuam para a compreensão da diversidade alfa e gama da microbiota da Caatinga; comparar a composição da mixobiota em áreas de caatinga situadas nos municípios de Serra Talhada (ST) e Mirandiba (M) com a encontrada em um enclave de floresta úmida (brejo de altitude) situado no município de Triunfo (T). Os espécimes foram coletados sobre restos lenhosos (173), folhedo (26), restos de plantas suculentas (3), casca de árvore viva (1) e fezes de herbívoros (1). Hemitrichia calyculata foi a espécie mais abundante (60 registros); outras espécies comuns foram Arcyria cinerea (20), Ceratiomyxa fruticulosa (19), A. denudata (16) e H. serpula (13). Apresenta-se uma lista comentada de 37 espécies, distribuídas em 17 gêneros, sete famílias e cinco ordens. A mixobiota dos três ambientes difere entre si: $\mathrm{CC}_{\mathrm{M} / \mathrm{TT}}=0,25 ; \mathrm{CC}_{\mathrm{M} / \mathrm{T}}=0,06 ; \mathrm{CC}_{\mathrm{ST} / \mathrm{T}}=0,39$. A relação espécie/gênero foi muito baixa na caatinga e relativamente alta na floresta úmida $\left(\mathrm{S} / \mathrm{G}_{\mathrm{M}}=1,0 ; \mathrm{S} / \mathrm{G}_{\mathrm{ST}}=1,3 ; \mathrm{S} / \mathrm{G}_{\mathrm{T}}=2,14\right)$. A abundância de espécimes e o número de espécies $(\mathrm{M}=4 / 4 ; \mathrm{ST}=26 / 12 ; \mathrm{T}=172 / 29)$ tendem a aumentar com a elevação da altitude e da pluviosidade. Fuligo megaspora é referida pela primeira vez para o Nordeste e Didymium perforatum é um novo registro para o Brasil.
\end{abstract}

Palavras-chave: Semiárido, florestas úmidas, mixobiota, Neotrópicos

\begin{abstract}
(Myxomycetes from caatinga and brejo de altitude areas in the semi-arid region of Pernambuco, Brazil). The Caatinga biome, situated in the Brazilian semi-arid region, is distributed among the territories of nine states, including Pernambuco. The objectives of this study were: (1) to understand the alpha and gamma diversity of the Caatinga myxobiota; and (2) to compare the composition of the myxobiota present in two areas of typical xerophilous vegetation situated in Serra Talhada (ST) and Mirandiba (M) municipalities with an enclave of rain forest situated in the municipality of Triunfo (T). Specimens were collected on woody debris (173), litter (26), debris of succulent plants (3), bark of a living tree (1) and dung (1). Hemitrichia calyculata was the most abundant species (60 records). Other common species were Arcyria cinerea (20), Ceratiomyxa fruticulosa (19), A. denudata (16) and H. serpula (13), which were collected during dry and humid periods. An annotated list is presented with records of 37 species from 17 genera, seven families and five orders. Myxomycetes assemblages differed from each other: $\mathrm{CC}_{\mathrm{M} / \mathrm{ST}}=0.25, \mathrm{CC}_{\mathrm{M} / \mathrm{T}}=0.06$, $\mathrm{CC}_{\mathrm{ST} / \mathrm{T}}=0.39$. The species/genus ratio was rather low in the caatinga and relatively high in the humid forest $\left(\mathrm{S} / \mathrm{G}_{\mathrm{M}}=\right.$ $\left.1.0, \mathrm{~S} / \mathrm{G}_{\mathrm{ST}}=1.3, \mathrm{~S} / \mathrm{G}_{\mathrm{T}}=2.14\right)$. Specimen abundance and the total number of species $(\mathrm{M}=4 / 4, \mathrm{ST}=26 / 12, \mathrm{~T}=172 / 29)$ increased with increasing precipitation and altitude. Fuligo megaspora is reported for the first time for the Northeast Region and Didymium perforatum is a new record for Brazil.
\end{abstract}

Key-words: Semi-arid, rainforest, myxobiota, Neotropics

\footnotetext{
${ }^{1}$ Universidade Federal de Pernambuco, Centro de Ciências Biológicas Programa de Pós-Graduação em Biologia de Fungos, Recife, PE, Brasil

${ }^{2}$ Universidade Federal de Pernambuco, Laboratório de Myxomycetes, Recife, PE, Brasil

${ }^{3}$ Autor para correspondência: laise@pq.cnpq.br
} 


\section{Introdução}

A Caatinga é o principal bioma da região Nordeste do Brasil, com fauna e flora adaptadas a fortes restrições hídricas decorrentes das precipitações pluviométricas escassas e irregulares, concentradas em um curto período do ano (Leal et al. 2003). Conforme as condições de solo e relevo, além da típica vegetação xerófila caducifólia espinhosa, podem ser encontrados enclaves de floresta úmida no semiárido brasileiro, conhecidos regionalmente como brejos de altitude (Alcoforado Filho et al. 2003).

Nas últimas décadas, pesquisadores tem se dedicado a avaliar a diversidade de Myxomycetes presentes em ambientes áridos e semiáridos no mundo, que abrigam uma mixobiota rica e diversificada (Blackwell \& Gilbertson 1980; Lado et al. 2007a, 2007b, 2009; Estrada-Torres et al. 2009; Novozhilov et al. 2003, 2006, 2010). No Brasil, desde os primeiros registros realizados por Gottsberger (1968) na Bahia, os estudos desenvolvidos em áreas de Caatinga, especialmente nos brejos de altitude, também apontam para a existência de uma mixobiota diversificada (Góes-Neto \& Cavalcanti 2002; Gusmão et al. 2005; Costa 2005; Cavalcanti et al. 2006; Costa et al. 2009, 2011; Alves et al. 2010; Ferreira \& Cavalcanti 2011).

No presente trabalho descreve-se a composição da mixobiota em três áreas situadas no semiárido pernambucano, sujeitas a condições distintas de cobertura vegetal, temperatura e umidade do solo e do ar, ampliando o conhecimento sobre a biodiversidade da Caatinga e a distribuição geográfica dos mixomicetos.

\section{Material e métodos}

Três expedições, com duração de cinco dias cada e mesmo esforço de coleta por área explorada, foram realizadas nas estações seca e chuvosa de 2011, em municípios localizados na Mesorregião do Sertão Pernambucano. Nesta região, as chuvas são escassas e mal distribuídas, com curto período chuvoso entre os meses de novembro e abril, sendo mais intenso de março até seu final.

\section{Áreas de estudo}

Mirandiba - Microrregião Salgueiro (08 ${ }^{\circ}{ }^{\prime} 13^{\prime \prime}$ 'S, $38^{\circ} 43^{\prime} 46^{\prime \prime} \mathrm{W}$, ca. $800 \mathrm{~km}^{2}, 450-750 \mathrm{~m}$ alt., clima BSh). A temperatura media anual é de $25,1^{\circ} \mathrm{C}$ e a precipitação média de $687 \mathrm{~mm} /$ ano. O tipo de vegetação predominante é a caatinga, com várias fitofisionomias (Alves et al. 2009). As coletas foram realizadas em caatinga arbustivo-arbórea, no Distrito de Serrotinho.

Serra Talhada - Microrregião do Pajeú (0759'31S, $38^{\circ} 17^{\prime} 54^{\prime \prime} \mathrm{W}$, ca $2.950 \mathrm{~km}^{2}, 429 \mathrm{~m}$ alt., clima BSh). A temperatura média anual é de $25,2^{\circ} \mathrm{C}$ e a precipitação média de $650 \mathrm{~mm} / \mathrm{ano}$, predominando a caatinga arbórea-arbustiva (Ferraz et al. 1998). As coletas foram realizadas na Estação Experimental do IPA.
Triunfo - Microrregião do Pajeú (07050'17”S, 3806’06”'W, ca $191,52 \mathrm{~km}^{2}, 1100 \mathrm{~m}$ alt., clima $\left.\mathrm{Cw}\right)$. As temperaturas médias mensais variam entre $18^{\circ} \mathrm{C}-22,5^{\circ} \mathrm{C}$, com registros de mínimas em torno de $12{ }^{\circ} \mathrm{C}$ e precipitação de $1222 \mathrm{~mm} /$ ano. A vegetação predominante é a floresta estacional subcaducifolia, característica de brejo de altitude (Ferraz et al. 1998). As coletas foram realizadas no Distrito de Santa Rita.

Em cada local, foram estabelecidos transectos de $100 \mathrm{~m}$, com pontos de coleta a cada $10 \mathrm{~m}$, examinando-se troncos e galhos em decomposição, folhedo, plantas suculentas, troncos de árvores vivas e excrementos de herbívoros. Os esporocarpos coletados foram herborizados e identificados com auxílio das monografias de Martin \& Alexopoulos (1969), Farr (1976) e Poulain et al. (2011). A descrição das espécies baseou-se no material coletado, visando informar características dos espécimes que ocorrem no Brasil. Exsicatas representativas do material estudado foram depositadas no herbário UFP. A distribuição mundial e nos Neotrópicos baseou-se em Martin \& Alexopoulos (1969), Farr (1976) e Lado \& Basanta (2008); a distribuição nas regiões e biomas do Brasil baseou-se em Cavalcanti et al. (2008), Bezerra et al. (2009), Alves et al. (2010), Agra et al. (2010), Ferreira \& Cavalcanti (2011) e Cavalcanti (2012). O índice de diversidade taxonômica $(S / G)$ e a semelhança entre o conjunto de espécies registradas nas áreas de estudo (CC) foram avaliados segundo Novozhilov et al. (2006).

\section{Resultados e discussão}

Um total de 204 espécimes foi coletado diretamente no campo, indicando a ocorrência de 37 espécies, distribuídas em 17 gêneros, sete famílias e cinco ordens, representando as três subclasses de Myxomycetes (Tab. 1). Os gêneros Diachea Fr. e Reticularia Bull. e 10 espécies são citados pela primeira vez para o ambiente de brejo de altitude. Cinco espécies são novas ocorrências para a Caatinga, dentre as quais uma constitui o primeiro registro para a Região Nordeste e outra para o Brasil.

\section{Lista comentada das espécies}

\section{Ceratiomyxaceae}

1. Ceratiomyxa fruticulosa (O.F. Müll.) T. Macbr., N. Amer. Slime-moulds, ed. 1 18. 1899

Esporóforo branco-leitoso a hialino, exosporado, ramificado, agrupado, elevando-se em colunas, 1,0-2,0 mm alt.; esporada branca; esporo elipsóide, hialino, liso, 5,0-10,0 $\times$ 8,0-13,0 $\mu \mathrm{m}$ diâm., preso ao esporóforo por filamento de comprimento uniforme em toda a frutificação.

Distribuição no Brasil: Norte (AM, AP, PA e RR), Nordeste (AL, BA, CE, PB, PI e RN), Sudeste (SP), Sul (RS e SC). Biomas: Amazônia, Caatinga, Cerrado e Mata Atlântica.

Material examinado selecionado: BRASIL. Pernambuco: Triunfo, 31/III/2011, tronco morto caído, Silva NA 104 (UFP 68448); ibidem, Silva NA 146 (UFP 68449); ibidem, 19/I/2011, Silva NA 89 (UFP 68447); ibidem, Silva NA 79 (UFP 68446). 
Comentários: cosmopolita, C. fruticulosa é uma espécie generalista, ocupando desde ambientes vegetacionais muito úmidos até os extremamente secos (Lado et al. 2003; Estrada-Torres et al. 2009; Rojas et al. 2008). Cavalcanti et al. (2008) apresentaram sua distribuição no Nordeste do Brasil, com a maior parte dos registros efetuada em fragmentos de Floresta Atlântica. Alves et al. (2010) citam sua ocorrência em áreas de caatinga arbórea e caatinga aberta, no Ceará. $\mathrm{Na}$ maioria das vezes $C$. fruticulosa comporta-se como lignícola, ocupando ocasionalmente outros microhabitats, sendo referida como suculentícola por Ferreira \& Cavalcanti (2011) para área de caatinga em Serra Talhada. No presente estudo, esta foi uma das poucas espécies assinaladas na caatinga de Mirandiba (1 espécime), ocorrendo também em Serra Talhada (três espécimes), esporulando sobre planta suculenta, e em Triunfo (15 espécimes), onde foi abundante e frequente em troncos mortos caídos (Tab. 1-2).

\section{Cribrariaceae}

1. Cribraria cancellata (Batsch) Nann.-Bremek., Nederlandse Myxomyceten (Zutphen) 92. 1975

Esporângio gregário, pendente, $3,42 \mathrm{~mm}$ alt.; esporoteca globosa, umbilicada na base, castanho-ferrugíneo, $0,53 \mathrm{~mm}$ diâm.; hipotalo membranáceo, irregular, castanho-enegrecido; pedicelo cilíndrico, castanho-enegrecido, mais claro e contorcido no ápice, base $0,11 \mathrm{~mm}$ larg., ápice $0,05 \mathrm{~mm}$ larg., 2,89 mm comp.; rede peridial castanha, formada por costelas longitudinais com filamentos delicados transversais conectando-as, calículo ausente; grânulo dictidino amarelo-alaranjado, 1,0 $\mu \mathrm{m}$ diâm.; esporada castanho-ferrugíneo; esporo globoso, verrucoso, castanho claro, 5,0-6,0 $\mu$ m diâm.

Material examinado selecionado: BRASIL. Pernambuco: Triunfo, 19/1/2011, tronco morto caído, Silva NA 12 (UFP 68461); ibidem, 08/VI/2011, Silva NA 172 (UFP 68462).

Distribuição no Brasil: Norte (AM e RR), Nordeste (AL, BA, CE, PB, PE, PI e SE), Sudeste (RJ e SP) e Sul (PR). Biomas: Amazônia, Cerrado e Mata Atlântica.

Comentários: espécie cosmopolita, assinalada em diferentes regiões e biomas do Brasil. Foi registrada tanto na caatinga, com dois espécimes coletados na estação chuvosa sobre troncos mortos, quanto no brejo de altitude, com seis espécimes, coletados nas estações seca e chuvosa (Tab. 1-2).

\section{Cribraria languescens Rex, Proc. Acad. Nat. Sci. Philadel-} phia 43: 394. 1891

Esporângio gregário ou isolado, pendente, 2,84-3,23 mm alt.; esporoteca subglobosa, castanho-cobre, $0,84-0,82 \mathrm{~mm}$ diâm., calículo profundo, persistindo até a metade; hipotalo membranáceo, inconspícuo, castanho-enegrecido; pedicelo cilíndrico, com estrias longitudinais, castanho escuro, mais claro no ápice, base $0,08 \mathrm{~mm}$ larg., ápice $0,03 \mathrm{~mm}$ larg., 3,36-3,23 mm comp.; grânulo dictidino presente tanto nos nódulos da rede peridial quanto na borda do calículo, castanho-alaranjados, 2,0 $\mu \mathrm{m}$ diâm.; esporada cobre; esporo globoso, verruculoso, castanho claro, 7,0 ㅆm diâm.
Distribuição no Brasil: Norte (AM), Nordeste (PE e SE), Sudeste (SP), Sul (SC); Biomas: Amazônia e Mata Atlântica. Material examinado selecionado: BRASIL. Pernambuco: Triunfo, 08/VI/2011, tronco morto caído, Silva NA 189 (UFP 68477). Serra Talhada, 10/VI/2011, tronco morto caído, Silva NA 260 (UFP 68476).

Comentários: esta espécie foi incluída por Stephenson et al. (2004) entre as 10 mais comuns em florestas úmidas neotropicais; também é citada para regiões áridas e frias da Rússia (Novozhilov et al. 2006, 2008). Um espécime foi coletado na caatinga de Serra Talhada e outro na floresta úmida de Triunfo, ambos na estação seca (Tab. 1), constituindo a primeira referência para a vegetação típica da Caatinga.

3. Cribraria splendens (Schrad.) Pers., Syn. meth. fung. 1: 191. 1801

Esporângio gregário, 2,2 $\mathrm{mm}$ alt.; esporoteca globosa, castanho-pardo, 0,58 $\mathrm{mm}$ diâm.; pedicelo castanho-enegrecido, cilíndrico, base 0,16 mm larg., ápice 0,05 mm larg., 1,62 mm comp.; hipotalo membranáceo, inconspícuo, castanho-enegrecido; rede peridial castanho com malhas unidas por membranas de mesma coloração; grânulo dictidino castanho, 1,0 $\mu \mathrm{m}$ diâm; esporada castanho-pardo; esporo globoso, verrucoso, castanho claro, 7,0 $\mu \mathrm{m}$ diâm.

Distribuição no Brasil: Nordeste (PE), Sudeste (SP). Bioma: Mata Atlântica.

Material examinado: BRASIL. Pernambuco: Triunfo, 08/VI/2011, tronco morto caído, Silva NA 164 (UFP 68519).

Comentários: com registros de ocorrência em países da Europa, Américas, Ásia e Oceania, até o momento $C$. splendens havia sido assinalada no Brasil apenas em fragmentos de Floresta Atlântica e áreas cultivadas situados em Pernambuco e São Paulo (Santos \& Cavalcanti 1991; Hochgesand \& Gottsberger 1996). Apenas um espécime foi obtido no presente estudo, coletado durante a estação chuvosa no brejo de altitude de Triunfo (Tab. 1). Referida pela primeira vez para a Caatinga.

\section{Cribraria violacea Rex, Proc. Acad. Nat. Sci. Philadelphia} 43: 393.1891

Esporângio gregário ou isolado, ereto, $1,24 \mathrm{~mm}$ alt.; esporoteca subglobosa, violeta escuro, $0,32 \mathrm{~mm}$ diâm.; pedicelo cilíndrico, base $0,05 \mathrm{~mm}$ larg., ápice $0,03 \mathrm{~mm}$ larg., 0,92 $\mathrm{mm}$ comp., estriado longitudinalmente, castanho-enegrecido; hipotalo circular, membranáceo, castanho-enegrecido; perídio simples, calículo ocupando metade ou pouco mais da esporoteca, rede peridial com grandes nódulos violeta claro, achatados, raras pontas livres; grânulo dictidino violeta, 1,0$2,0 \mu \mathrm{m}$ diâm; esporada violeta muito escuro; esporo globoso, levemente verrucoso, violeta claro, 6,0-8,0 $\mu \mathrm{m}$ diâm.

Distribuição no Brasil: Nordeste (AL, BA, PB, PE, PI, RN e SE), Sudeste (SP), Sul (SC). Biomas: Caatinga e Mata Atlântica.

Material examinado selecionado: BRASIL. Pernambuco: Serra Talhada, 10/VI/2011, tronco morto caído, Silva NA 248 (UFP 68518). 
Comentários: Cribraria violacea tem registros em quase todo o Nordeste e alguns estados do Sul e Sudeste. Foi assinalada por Gusmão et al. (2005) em caatinga arbustiva na Chapada Diamantina, Bahia. No presente estudo foram obtidos dois espécimes, coletados em Mirandiba e Serra Talhada, esporulando sobre tronco morto, um na estação chuvosa e outro na estação seca (Tab. 1-2).

\section{Didymiaceae}

1. Didymium clavus (Alb. \& Schwein.) Rabenh., Deutschl. Krypt.-Fl. 1:280.1844

Esporângio gregário, ereto, $0,66 \mathrm{~mm}$ alt.; esporoteca discóide, umbilicada na base, branco a cinza, $0,18 \mathrm{~mm}$ diâm.; pedicelo cilíndrico, estriado longitudinalmente, castanho-enegrecido na base $(0,11 \mathrm{~mm}$ larg.) clareando para o ápice (0,08 mm larg.), 0,48 mm comp.; hipotalo membranáceo, discoide, castanho-enegrecido; perídio membranáceo, simples, castanho, coberto com cristais de cálcio, deiscência circuncisa, persistindo na base; capilício ramificado, hialino, ondulado; columela discoide, castanho escuro; esporada castanho escuro; esporo globoso, verrucoso, castanho claro, 6,0-7,0 $\mu \mathrm{m}$ diâm.

Distribuição no Brasil: Norte (RR), Nordeste (BA, PE, PI e SE), Sudeste (SP), Sul (PR, RS e SC). Biomas: Amazônia e Mata Atlântica.

Material examinado selecionado: BRASIL. Pernambuco: Triunfo, 19/I/2011, folhedo, Silva NA 85 (UFP 68524).

Comentários: com ampla distribuição mundial, $D$. clavus tem registros em 12 países neotropicais, tanto em ambientes úmidos como áridos, e já foi assinalada em quase todas as regiões do Brasil. Apesar de ter sido referida para a região semiárida do Piauí, não foi incluída por Cavalcanti (2012) entre as espécies ocorrentes na Caatinga, por não ter sido coletada na vegetação típica deste bioma. No presente estudo, dois exemplares foram coletados sobre folha morta, na estação chuvosa, em Triunfo (Tab. 1-2).

\section{Didymium nigripes (Link) Fr., Syst. mycol. 3: 1191829}

Esporângio gregário, 1,13-1,32 mm alt.; esporoteca subglobosa, umbilicada na base, branco-cinza, 0,37-0,53 $\mathrm{mm}$ diâm.; hipotalo membranáceo, circular, castanho escuro; pedicelo cilíndrico, estriado longitudinalmente, castanho-enegrecido na base $(0,08-0,11 \mathrm{~mm}$ larg.) clareando para o ápice (0,05-0,06 mm larg.), 0,79-0,81 mm comp.; perídio membranáceo, simples, castanho claro, coberto com cristais de cálcio, deiscência apical irregular, persistindo na base da esporoteca; capilício delicado, ramificado, castanho-avermelhado; columela globosa, castanho, calcária, 189,0 $\mu \mathrm{m}$ comp. e 93,0 $\mu \mathrm{m}$ larg.; esporada castanha; esporo globoso, verrucoso, castanho claro, 8,0-9,0 $\mu \mathrm{m}$ diâm.

Distribuição no Brasil: Norte (RR), Nordeste (PE e PI), Sudeste (RJ e SP), Sul (RS). Biomas: Amazônia e Mata Atlântica.

Material examinado selecionado: BRASIL. Pernambuco: Triunfo, 19/I/2011, folhedo, Silva NA 20 (UFP 68521); ibidem, Silva NA 31 (UFP 68520).
Comentários: cosmopolita, $D$. nigripes tem registros em diferentes regiões e biomas do Brasil. É referida para a região semiárida do Piauí, porém os esporocarpos foram encontrados em enclaves de cerrado (Cavalcanti \& Mobin 2004). Os dois espécimes obtidos no presente estudo foram coletados durante a estação chuvosa no folhedo de solo do brejo de altitude (Tab.1-2).

3. Didymium perforatum Yamash., J. Sci. Hiroshima Univ., Ser. B, Div.2, Bot. 3: 33.1936

Plasmodiocarpo reticulado, ca. 2,5 cm comp., $1,3 \mathrm{~cm}$ larg.; hipotalo inconspícuo; perídio membranáceo, azulado, iridescente, coberto com cristais de cálcio, deiscência irregular; capilício ramificado, hialino, 1,0 $\mu \mathrm{m}$ diâm.; esporada castanho-enegrecido; esporo castanho, subgloboso, espinuloso, 9,0-10,0 $\mu$ m diâm.

Distribuição no Brasil: primeiro registro para o país.

Material examinado selecionado: BRASIL. Pernambuco: Triunfo, 19/I/2011, folhedo, Silva NA 28 (UFP 68450); ibidem, Silva NA 44 (UFP 68455); ibidem, Silva NA 38 (UFP 68452); ibidem, Silva NA 46 (UFP 68456); ibidem, Silva NA 63 (UFP 68457); ibidem, Silva NA 39 (UFP 68453).

Comentários: Didymium perforatum é uma espécie rara, descrita por M. Yamashiro em 1936, com base em material coletado sobre folhas mortas em Kyûsyû, no Japão. Ocorre também na China, sobre folhedo e na revisão feita por Lado \& Basanta (2008) para os Neotrópicos é referida apenas para a Argentina. Os 15 espécimes obtidos foram encontrados na estação chuvosa no brejo de altitude em apenas uma excursão, mas eram abundantes sobre o folhedo (Tab. 1-2). O plasmodiocarpo reticulado e o perídio iridescente permitiram identificar seguramente a espécie, referida pela primeira vez para o Brasil.

4. Didymium squamulosum (Alb. \& Schwein.) Fr., in Fries \& Palmquist, Symb. gasteromyc. 3: 19.1818

Esporângio gregário, 0,82-1,19 mm alt.; esporoteca globosa a semi-globosa, umbilicada na base, cinza, 0,43-0,53 mm diâm.; hipotalo membranoso, castanho-enegrecido; pedicelo cilíndrico, estriado longitudinalmente, castanho-enegrecido na base $(0,11-0,16 \mathrm{~mm})$ mais claro no ápice (0,06-0,08 mm), 0,4-0,7 mm comp.; perídio membranoso, simples, coberto com cristais de cálcio, parcialmente persistente; capilício ramificado, hialino; columela globosa, branca; esporada castanho escuro; esporo globoso, densamente verrucoso, castanho, 8,0-10,0 $\mu \mathrm{m}$ diâm.

Distribuição no Brasil: Nordeste (BA, PE e RN), Sudeste (SP), Sul (SC). Biomas: Caatinga e Mata Atlântica.

Material examinado selecionado: BRASIL. Pernambuco: Triunfo, 19/I/2011, folhedo, Silva NA 88 (UFP 68529); ibidem, Silva NA 87 (UFP 68528); ibidem, 31/III/2011, Silva NA 99 (UFP 68527); Serra Talhada, 20/I/2011, folhedo, Silva NA 94 (UFP 68526).

Comentários: com ampla distribuição mundial e registros para 23 países neotropicais, D. squamulosum ocupa diferentes microhabitats, de preferência em florestas úmidas, 
Tabela 1. Distribuição das espécies de mixomicetos nos ambientes de caatinga e brejo de altitude no levantamento efetuado nos municípios de Serra Talhada, Mirandiba e Triunfo, Sertão de Pernambuco.

\begin{tabular}{|c|c|c|c|c|c|c|c|}
\hline \multirow{4}{*}{ Táxon } & \multicolumn{6}{|c|}{ Número de espécimes } & \multirow{4}{*}{ Total } \\
\hline & \multirow{2}{*}{\multicolumn{2}{|c|}{$\begin{array}{c}\begin{array}{c}\text { Caatinga } \\
\text { Serra Talhada }\end{array} \\
\text { Estação } \\
\end{array}$}} & \multirow{2}{*}{\multicolumn{2}{|c|}{$\begin{array}{c}\begin{array}{c}\text { Caatinga } \\
\text { Mirandiba }\end{array} \\
\text { Estação }\end{array}$}} & \multicolumn{2}{|c|}{ Brejo de altitude Triunfo } & \\
\hline & & & & & & & \\
\hline & chuvosa & seca & chuvosa & seca & chuvosa & seca & \\
\hline \multicolumn{8}{|c|}{ Ceratiomyxales, Ceratiomyxaceae, Ceratiomyxa } \\
\hline C. fruticulosa (O.F. Müll.) T. Macbr. & 2 & 1 & 1 & 0 & 13 & 2 & 19 \\
\hline \multicolumn{8}{|c|}{ Liceales, Cribrariaceae, Cribraria } \\
\hline C. cancellata (Batsch) Nann.-Bremek. & 2 & 0 & 0 & 0 & 4 & 2 & 8 \\
\hline C. languescens Rex & 0 & 1 & 0 & 0 & 0 & 1 & 2 \\
\hline C. splendens (Schrad.) Pers. & 0 & 0 & 0 & 0 & 0 & 1 & 1 \\
\hline C. violacea $\mathrm{Rex}$ & 0 & 1 & 1 & 0 & 0 & 0 & 2 \\
\hline \multicolumn{8}{|c|}{ Liceales, Reticulariaceae, Dictydiaethalium } \\
\hline D. plumbeum (Schumach.) Rostaf. & 0 & 0 & 0 & 0 & 1 & 0 & 1 \\
\hline \multicolumn{8}{|c|}{ Liceales, Reticulariaceae, Lycogala } \\
\hline L. epidendrum (L.) Fr. & 0 & 0 & 0 & 0 & 4 & 0 & 4 \\
\hline L. exiguum Morgan & 0 & 0 & 0 & 0 & 2 & 1 & 3 \\
\hline \multicolumn{8}{|c|}{ Liceales, Reticulariaceae, Reticularia } \\
\hline R. jurana Meyl. & 0 & 0 & 0 & 0 & 1 & 0 & 1 \\
\hline \multicolumn{8}{|c|}{ Liceales, Reticulariaceae, Tubifera } \\
\hline T. microsperma (Berk. \& M. A. Curtis) G.W. Martin & 0 & 0 & 0 & 0 & 0 & 1 & 1 \\
\hline \multicolumn{8}{|c|}{ Trichiales, Trichiaceae, Arcyria } \\
\hline A. cinerea (Bull.) Pers & 1 & 4 & 0 & 0 & 6 & 9 & 20 \\
\hline A. denudata (L.) Wettst. & 0 & 0 & 0 & 0 & 6 & 10 & 16 \\
\hline \multicolumn{8}{|c|}{ Trichiales, Trichiaceae, Hemitrichia } \\
\hline H. calyculata (Speg.) M.L. Farr & 1 & 3 & 0 & 0 & 25 & 31 & 60 \\
\hline H. serpula (Scop.) Rostaf. ex Lister & 0 & 4 & 0 & 0 & 6 & 3 & 13 \\
\hline \multicolumn{8}{|c|}{ Physarales, Didymiaceae, Diachea } \\
\hline D. leucopodia (Bull.) Rostaf. & 0 & 0 & 0 & 0 & 1 & 0 & 1 \\
\hline \multicolumn{8}{|c|}{ Physarales, Didymiaceae, Didymium } \\
\hline D. clavus (Alb. \& Schwein.) Rabenh. & 0 & 0 & 0 & 0 & 2 & 0 & 2 \\
\hline D. nigripes (Link) Fr. & 0 & 0 & 0 & 0 & 2 & 0 & 2 \\
\hline D. perforatum Yamash. & 0 & 0 & 0 & 0 & 15 & 0 & 15 \\
\hline D. squamulosum (Alb. \& Schwein.) Fr. & 1 & 0 & 0 & 0 & 4 & 0 & 5 \\
\hline \multicolumn{8}{|c|}{ Physarales, Physaraceae, Badhamia } \\
\hline B. melanospora Speg. & 0 & 0 & 1 & 0 & 0 & 0 & 1 \\
\hline \multicolumn{8}{|c|}{ Physarales, Physaraceae, Craterium } \\
\hline C. leucocephalum (Pers. ex J.F. Gmel.) Ditmar & 1 & 0 & 0 & 0 & 0 & 0 & 1 \\
\hline \multicolumn{8}{|c|}{ Physarales, Physaraceae, Fuligo } \\
\hline F. megaspora Sturgis & 2 & 0 & 0 & 0 & 0 & 0 & 2 \\
\hline \multicolumn{8}{|c|}{ Physarales, Physaraceae, Physarum } \\
\hline P. album (Bull.) Chevall. & 0 & 0 & 0 & 0 & 0 & 1 & 1 \\
\hline P. bogoriense Racib. & 0 & 0 & 0 & 0 & 0 & 1 & 1 \\
\hline P. cinereum (Batsch) Pers. & 0 & 0 & 0 & 0 & 1 & 0 & 1 \\
\hline P. compressum Alb. \& Schwein. & 0 & 0 & 0 & 0 & 1 & 0 & 1 \\
\hline
\end{tabular}




\begin{tabular}{|c|c|c|c|c|c|c|c|}
\hline \multirow{4}{*}{ Táxon } & \multicolumn{6}{|c|}{ Número de espécimes } & \multirow{4}{*}{ Total } \\
\hline & \multirow{2}{*}{\multicolumn{2}{|c|}{$\begin{array}{c}\begin{array}{c}\text { Caatinga } \\
\text { Serra Talhada }\end{array} \\
\text { Estação }\end{array}$}} & \multirow{2}{*}{\multicolumn{2}{|c|}{$\begin{array}{c}\begin{array}{c}\text { Caatinga } \\
\text { Mirandiba }\end{array} \\
\text { Estação }\end{array}$}} & \multicolumn{2}{|c|}{ Brejo de altitude Triunfo } & \\
\hline & & & & & \multicolumn{2}{|c|}{ Estação } & \\
\hline & chuvosa & seca & chuvosa & seca & chuvosa & seca & \\
\hline P. echinosporum Lister & 1 & 0 & 0 & 0 & 0 & 0 & 1 \\
\hline P. nucleatum Rex & 0 & 0 & 0 & 0 & 0 & 1 & 1 \\
\hline P. rigidum (G. Lister) G. Lister & 0 & 0 & 0 & 0 & 1 & 0 & 1 \\
\hline P. stellatum(Massee) G.W. Martin & 0 & 0 & 0 & 0 & 2 & 3 & 5 \\
\hline P. tenerum Rex & 0 & 0 & 0 & 0 & 1 & 1 & 2 \\
\hline \multicolumn{8}{|c|}{ Stemonitales, Stemonitaceae, Comatricha } \\
\hline C. pulchella (C. Bab.) Rostaf. & 0 & 0 & 0 & 0 & 0 & 1 & 1 \\
\hline \multicolumn{8}{|c|}{ Stemonitales, Stemonitaceae, Stemonitis } \\
\hline S. axifera (Bull.) T. Macbr. & 1 & 0 & 0 & 0 & 1 & 1 & 3 \\
\hline S. fusca Roth & 2 & 0 & 0 & 0 & 0 & 0 & 2 \\
\hline S. splendens Rostaf. & 0 & 0 & 0 & 0 & 1 & 0 & 1 \\
\hline \multicolumn{8}{|c|}{ Stemonitales, Stemonitaceae, Stemonitopsis } \\
\hline S. subcaespitosa (Peck) Nann.-Bremek. & 0 & 0 & 1 & 0 & 0 & 0 & 1 \\
\hline S. typhina (F.H. Wigg.) Nann.-Bremek. & 0 & 0 & 0 & 0 & 0 & 2 & 2 \\
\hline Total & 14 & 14 & 4 & 0 & 100 & 72 & 204 \\
\hline
\end{tabular}

Tabela 2. Grupos ecológicos de mixomicetos registrados nos ambientes de caatinga e brejo de altitude no levantamento efetuado nos municípios de Serra Talhada, Mirandiba e Triunfo, Sertão de Pernambuco.

\begin{tabular}{|c|c|}
\hline $\begin{array}{l}\text { Grupo ecológico } \\
\text { (número de espécimes) }\end{array}$ & Espécies (número de espécimes) \\
\hline Lignícola (173) & $\begin{array}{l}\text { Arcyria cinerea (20), A. denudata (16); Ceratiomyxa fruticulosa (18); Cribraria cancellata (8), C. languescens (2), C. splendens } \\
\text { (1), C. violacea (2); Diachea leucopodia (1); Dictydiaethalium plumbeum (1); Didymium squamulosum (2); Fuligo megaspora } \\
\text { (2); Hemitrichia calyculata (59), H. serpula (13); Lycogala epidendrum (4), L. exiguum (3); Physarum album (1), P. compressum } \\
\text { (1), P. echinosporum (1), P. rigidum (1), P. stellatum (4), P. tenerum (2); Reticularia jurana (1); Stemonitis axifera (3), } \\
\text { S. fusca (2), S. splendens (1); Stemonitopsis subcaespitosa (1), S. typhina (2); Tubifera microsperma (1). }\end{array}$ \\
\hline Foliícola (26) & $\begin{array}{l}\text { Didymium clavus (2), D. nigripes (2), D. perforatum (15), D. squamulosum (3); } \\
\text { Physarum bogoriense (1), P. cinereum (1), P. nucleatum (1), P. stellatum (1). }\end{array}$ \\
\hline Suculentícola (3) & Badhamia melanospora (1); Ceratiomyxa fruticulosa (1); Craterium leucocephalum (1). \\
\hline Fimícola (1) & Hemitrichia calyculata (1). \\
\hline Corticícola (1) & Comatricha pulchella (1). \\
\hline
\end{tabular}

sendo rara em regiões áridas e semiáridas. No Brasil, tem ocorrência conhecida para a Mata Atlântica e foi referida para a Caatinga por Ferreira \& Cavalcanti (2011), esporulando sobre Opuntia sp., enquadrando-se como acidental na mixobiota de Serra Talhada. No presente trabalho, foram obtidos quatro espécimes em Triunfo e um em Serra Talhada, coletados na estação chuvosa (Tab. 1).

5. Diachea leucopodia (Bull.) Rostaf., Sluzowce monogr. 190. 1874

Esporângio gregário, 1,68 mm alt.; esporoteca cilíndrica, castanho-cinza, 0,84 $\mathrm{mm}$; hipotalo pouco desenvolvido, branco-giz; pedicelo cilíndrico, branco-giz, base $0,47 \mathrm{~mm}$, ápice $0,11 \mathrm{~mm}, 0,81 \mathrm{~mm}$ comp.; perídio simples, membranáceo, iridescente, parcialmente persistente; columela afinando para o ápice, branco-giz; capilício ramificado, castanho-ferrugíneo, mais claro nas pontas; esporada castanho-púrpura; esporo globoso, verruculoso, castanho-ferrugíneo, 9,0 $\mu$ m diâm.

Distribuição no Brasil: Nordeste (BA, PE, PI e RN), Sudeste (MG e SP), Sul (PR, RS e SC). Biomas: Caatinga e Mata Atlântica.

Material examinado selecionado: BRASIL. Pernambuco: Triunfo, 19/I/2011, folhedo, Silva NA 74 (UFP 68466). 
Comentários: cosmopolita, presente em diversos ambientes, incluindo manguezais (Cavalcanti et al. 2008), D. leucopodia foi referida para o bioma Caatinga por Cavalcanti et al. (2009). Ferreira \& Cavalcanti (2011) assinalaram a presença desta espécie na caatinga de Mirandiba, embora acidental e escassa, esporulando sobre espinhos de Pilosocereus gounellei F.A.C. Weber ex K. Schum. No presente estudo, esporocarpos de D. leucopodia foram observados no folhedo do brejo de altitude, onde se obteve apenas um espécime, esporulado durante a estação chuvosa (Tab. 1-2).

\section{Physaraceae}

1. Badhamia melanospora Speg., Anales Soc. Ci. Argent. 10: 150.1880

Esporângio gregário, 0,09-0,11 mm alt.; esporoteca reniforme, umbilicada na base, branca, $1 / 2$ da altura total; hipotalo membranáceo, castanho claro; pedicelo contorcido, castanho claro, base $0,02 \mathrm{~mm}$, ápice $0,01 \mathrm{~mm}, 0,05-0,06 \mathrm{~mm}$ comp.; perídio membranáceo, hialino, simples, parcialmente persistente, com grânulos de cálcio esparsos; capilício escasso, fortemente calcário; esporada castanho-enegrecido; esporo globoso, verrucoso, castanho escuro, com grupos de verrugas, $11,0-14,0 \mu \mathrm{m}$ diâm.

Distribuição no Brasil: Nordeste (PE e RN), Sul (RS). Biomas: Caatinga e Mata Atlântica.

Material examinado selecionado: BRASIL. Pernambuco: Triunfo, 19/I/2011, folhedo, Silva NA 11 (UFP 68471); Mirandiba, 18/I/2011, planta suculenta, Silva NA 26 (UFP 68472).

Comentários: o material tipo desta espécie foi coletado sobre cactácea na América do Sul e desde então tem sido frequentemente encontrada em regióes áridas da América do Norte e do Sul, bem como em países da Europa e África (Beltran-Tejera et al. 2010). Investigando a presença de mixomicetos em cactáceas, Ferreira \& Cavalcanti (2011) relatam que $B$. melanospora foi a espécie mais abundante e frequente, caracterizando a mixobiota de Serra Talhada. No presente estudo, apenas um espécime foi obtido, esporulando na estação chuvosa sobre folhas mortas, em Mirandiba (Tab. 1-2).

\section{Craterium leucocephalum (Pers. ex J.F. Gmel.) Ditmar, in}

Sturm, Deutschl. Fl. Pilze 1(1): 21.1813

Esporângio gregário, $1,30 \mathrm{~mm}$ alt.; esporoteca piriforme, castanho; pedicelo cilíndrico, castanho, 0,66 $\mathrm{mm}$ comp.; hipotalo membranáceo, discoide, castanho; perídio simples, persistindo na forma de calículo fundo; capilício com filamentos hialinos e nódulos brancos de cálcio, irregulares; pseudocolumela calcária; esporada castanho; esporo globoso, verrucoso, castanho, $8,0 \mu \mathrm{m}$ diâm.

Distribuição no Brasil: Norte (AM e RR), Nordeste (BA, PB, PE, PI, RN e SE), Sudeste (RJ e SP), Sul (PR, RS e SC). Biomas: Amazônia, Caatinga e Mata Atlântica.

Material examinado: BRASIL. Pernambuco: Serra Talhada, 20/I/2011, folhedo, Silva NA 93 (UFP 68467).
Comentários: cosmopolita, C. leucocephalum tem ampla distribuição nos Neotrópicos, com registros para 17 países. Ocorre frequentemente em ambientes úmidos de florestas temperadas e tropicais, mas já foi encontrada em ecossistemas áridos, como a Reserva da Biosfera do vale de Tehuacán-Cuicatlán, no México (Estrada-Torres et al. 2009). Foi assinalada nos biomas Amazônia e Mata Atlântica, sendo menos comum na Caatinga, para onde foi relatada por Alves et al. (2010), com base em material coletado em Ibiapina, no Ceará. No presente estudo, apenas um espécime foi coletado, esporulando na estação chuvosa sobre folhas mortas, na caatinga de Serra Talhada (Tab. 1-2).

\section{Fuligo megaspora Sturgis, Colorado Coll. Stud. Sci. Ser. 12:443.1913}

Etálio pulvinado 2,5-4,0 cm diâm.; córtex espesso, esponjoso, calcário, branco-cinza; capilício escasso, delicado, hialino; esporada castanha; esporo globoso, castanho escuro, com espinhos grandes formando retículos incompletos, 15,0 $\mu \mathrm{m}$ diâm.

Distribuição no Brasil: Sudeste (SP). Bioma: Mata Atlântica.

Material examinado: BRASIL. Pernambuco: Serra Talhada, 20/I/2011, folhedo, Silva NA 93 (UFP 68467).

Comentários: Fuligo megaspora foi descrito por W. C. Sturgis, com base em material coletado nas Montanhas Cheyenne, no Colorado, onde o clima é muito seco, semiárido (Lister 1925). Diferencia-se das outras espécies do gênero pela coloração do etálio e pela dimensão, coloração e ornamentação do esporo, interpretada por Sturgis como "closely and coarsely tuberculate, the tubercules sometimes arranged in irregular lines"(Keller \& Schoknecht 1989). Registros posteriores evidenciaram sua ocorrência no deserto de Sonora, no Arizona (Bates \& Barber 2008). Embora rara, F. megaspora ocorre em países da Europa, América do Norte, África e Ásia; nos Neotrópicos, tem registros para cinco países. Foi citada para o Brasil por Farr (1976), com indicação de exsicata no Herbário FH, porém o único exemplar do gênero presente na coleção proveniente do Brasil (00265550), coletado no Rio de Janeiro em 1929, está identificado como F. septica. Hochgesand \& Gottsberger (1996) a referem para Botucatu, SP, no domínio da Mata Atlântica, mas comentam que o material, desenvolvido em câmara-úmida, estava imaturo e não indicam depósito em herbário. Na coleção do Herbário MMEY a exsicata DEF 18279, identificada como $F$. megaspora, foi coletada no Brasil em 2000 por J. P. Hoof; na etiqueta do herbário consta o Paraná como estado de origem, porém as coordenadas geográficas $\left(5^{\circ} 7^{\prime} \mathrm{S}\right.$ e $40^{\circ}$ $85^{`}$ WG) indicam que procede do Nordeste. No presente estudo, foram coletados dois espécimes em Serra Talhada, na estação chuvosa (Tab. 1), ambos apresentando etálios e esporos típicos da espécie. Esta é a primeira referência de F. megaspora para o Nordeste do Brasil e para o bioma Caatinga. 
4. Physarum album (Bull.) Chevall., Fl. gén. env. Paris 1: 336 (1826)

Esporângio gregário, $0,94 \mathrm{~mm}$ alt.; esporoteca semi-globosa, umbilicada, castanho-enegrecida, 0,18 mm diâm.; hipotalo membranáceo, castanho-enegrecido; pedicelo cilíndrico, castanho-enegrecido na base $(0,13 \mathrm{~mm}$ larg.) clareando para o ápice (0,08 $\mathrm{mm}$ larg.), 0,76 mm comp.; perídio membranáceo, simples, deiscência areolada; capilício ramificado, escasso, hialino, nódulo de cálcio branco; esporada castanho-enegrecido; esporo globoso, verrucoso, castanho-lilás, 9,0 ㅆ diâm.

Distribuição no Brasil: Nordeste (AL, BA, CE, MA, PB, PE, PI, RN e SE), Sudeste (ES, MG, RJ e SP), Sul (PR, RS e SC). Biomas: Caatinga, Cerrado e Mata Atlântica.

Material examinado: BRASIL. Pernambuco: Triunfo, 08/VI/2011, tronco morto caído, Silva NA 205 (UFP 68510).

Comentários: com ampla distribuição nos Neotrópicos, onde ocorre em 20 países e com registros em todos os estados do Nordeste, Sudeste e Sul do país, P. album foi assinalada em diferentes biomas, incluindo a Caatinga e seus brejos de altitude (Silva \& Cavalcanti 1988; Alves et al. 2010). Estrada-Torres et al. (2009) comentam sua presença frequente no vale de Tehuacán-Cuicatlán, México, ocupando diferentes microhabitats, sendo também referida para zonas áridas e frias da Sibéria, onde comporta-se frequentemente como lignícola (Kosheleva et al. 2008). No presente estudo, foi obtido apenas um espécime, coletado durante a estação seca no brejo de altitude, sobre tronco em decomposição (Tab. 1-2).

\section{Physarum bogoriense Racib., Hedwigia 37(1): 52. 1898}

Plasmodiocarpo gregário, branco e bege; perídio duplo, camada interna membranosa, delicada e iridescente e a camada externa cartilaginosa bege; deiscência longitudinal por lobos reflexos, persistindo irregularmente; pseudocolumela calcaria; capilício castanho claro, escasso, nódulo de cálcio branco; esporada castanho-enegrecido; esporo castanho escuro, verrucoso, 12,0 $\mu \mathrm{m}$ diâm.

Distribuição no Brasil: Nordeste (AL, BA, PB, PE, PI e SE), Sudeste (SP), Sul (RS e SC). Biomas: Caatinga, Cerrado e Mata Atlântica.

Material examinado: BRASIL. Pernambuco: Triunfo, 08/VI/2011, folhedo, Silva NA 203 (UFP 68463).

Comentários: tipicamente tropical, ocorrendo na América do Norte, Central e do Sul, P. bogoriense foi assinalada no Nordeste, Sudeste e Sul do país. Sua presença no semiárido brasileiro foi registrada pela primeira vez por Gottsberger (1968), com base em material coletado em Gameleira dos Crentes, na Bahia. Foi enquadrada por Ferreira \& Cavalcanti (2011) como acessória e ocasional na mixobiota suculentícola de Serra Talhada e Mirandiba. O único espécime obtido foi coletado durante a estação seca no folhedo em Triunfo (Tab. 1-2), apresentando esporos com dimensões maiores que as comumente descritas para a espécie. Este é o primeiro registro de $P$. bogoriense em brejo de altitude.
6. Physarum cinereum (Batsch) Pers., Neues Mag. Bot. 1:89. 1794

Plasmodiocarpo gregário, curto, séssil, cinza; perídio membranáceo, simples, coberto por grânulos de cálcio, deiscência irregular; capilício abundante, nódulo de cálcio anguloso, branco; esporada castanho-enegrecida; esporo castanho claro, verrucoso, globoso, 8,0-10,0 $\mu \mathrm{m}$ diâm.

Distribuição no Brasil: Norte (AM), Nordeste (AL, BA, PE, PI e SE), Sudeste (MG e SP), Sul (SC). Biomas: Amazônia e Mata Atlântica.

Material examinado: BRASIL. Pernambuco: Triunfo, 19/I/2011, folhedo, Silva NA 19 (UFP 68474).

Comentários: com registros para 22 países dos Neotrópicos, incluindo zonas úmidas e áridas do México (Lado et al. 2003; Estrada-Torres et al. 2009), P cinereum tem ampla distribuição no Brasil. Na Região Nordeste do país, P. cinereum foi assinalada apenas em enclaves de cerrado, mata ciliar e mata úmida em Alagoas, Bahia, Pernambuco e Sergipe (Góes-Neto \& Cavalcanti 2002; Bezerra et al. 2008), sendo esta a primeira referência para Caatinga. $\mathrm{O}$ único espécime obtido foi coletado sobre folhas mortas durante a estação chuvosa, no brejo de altitude de Triunfo (Tab. 1-2).

7. Physarum compressum Alb. \& Schwein., Consp. fung. lusat. 97. 1805

Esporângio gregário, 1,2 mm alt.; esporoteca em forma de leque, cinza, comprimida lateralmente; hipotalo membranáceo, inconspícuo, cinza; pedicelo cilíndrico, curto, cinza; perídio membranáceo, simples, deiscência apical irregular; capilício hialino com nódulos de cálcio branco variando em forma e tamanho; esporada castanho-enegrecida; esporo globoso, verrucoso, castanho, 12,0 $\mu \mathrm{m}$ diâm.

Distribuição no Brasil: Nordeste (AL, BA, CE, MA, PE e SE), Sudeste (SP), Sul (PR, RS e SC). Biomas: Caatinga e Mata Atlântica.

Material examinado selecionado: BRASIL. Pernambuco: Triunfo, 19/1/2011, folhedo, Silva NA 37 (UFP 68475).

Comentários: com ampla distribuição geográfica, $P$. compressum tem ocorrência conhecida para 24 países neotropicais. No Brasil, foi assinalada no Nordeste, Sudeste e Sul, em ambientes vegetacionais secos ou úmidos. Cavalcanti et al. (2006) referem esta espécie para o semiárido cearense e pernambucano, em vegetação típica de caatinga e nos enclaves florestais úmidos. Ferreira \& Cavalcanti (2011) comentam que $1 / 3$ dos espécimes coletados sobre cactáceas em Serra Talhada e em Mirandiba pertenciam a P. compressum, porém no presente estudo, o único registro obtido foi efetuado no brejo de altitude, onde os esporocarpos foram encontrados sobre tronco morto, na estação chuvosa (Tab. 1-2).

\section{Physarum echinosporum Lister, J. Bot. 37: 147. 1899}

Plasmodiocarpo isolado, branco-giz, curto, sinuoso, fortemente comprimido lateralmente, 0,5-2,0 mm comp.; perídio duplo, persistente, internamente membranoso quase hialino e externamente calcário e branco, deiscência apical; 
capilício amarelo claro, nódulo de cálcio branco; hipotalo inconspícuo; esporada castanho-enegrecido; esporo globoso, espinuloso, castanho-enegrecido, 11,0 $\mu \mathrm{m}$ diâm.

Distribuição no Brasil: Nordeste (PE e RN), Sudeste (RJ e SP). Biomas: Caatinga e Mata Atlântica.

Material examinado: BRASIL. Pernambuco: Serra Talhada, 20/I/2011, tronco morto caído, Silva NA 97 (UFP 68473).

Comentários: com distribuição centrada nos trópicos, P. echinosporum ocorre em países da África, Ásia, Américas e Europa, presente em diversos ambientes, incluindo regiões desérticas (Fenouil 2004; Lado et al. 2007a; Ndiritu et al. 2009). Foi referida pela primeira vez para o bioma Caatinga por Ferreira \& Cavalcanti (2011), esporulando sobre cactáceas nas estações seca e chuvosa. Os referidos autores enquadraram esta espécie como acessória e ocasional na mixobiota de Mirandiba e Serra Talhada, porém no presente estudo se obteve apenas um espécime, esporulado sobre tronco em decomposição, durante a estação chuvosa (Tab. 1-2).

9. Physarum nucleatum Rex, Proc. Acad. Nat. Sci. Philadelphia 43: 389.1891

Esporângio gregário, 1,66 mm alt.; esporoteca globosa, cinza, $0,42 \mathrm{~mm}$ diâm.; perídio membranáceo, simples, persistente, deiscência petalóide; pedicelo castanho claro, cilíndrico, base 0,16 mm larg., ápice 0,03 $\mathrm{mm}$ larg. e 1,24 mm comp.; hipotalo membranáceo, circular, castanho claro; capilício hialino, dicotomicamente ramificado, nódulo de cálcio 9,3 × 7,8 $\mu \mathrm{m}$ diâm., branco; pseudocolumela globosa, calcária, branca; esporada castanha; esporo globoso, castanho-violáceo, quase liso a levemente verrucoso, 8,0 $\mu \mathrm{m}$ diâm.

Distribuição no Brasil: Norte (AM e RR), Nordeste (AL, CE, PE, PI e SE), Sudeste (SP), Sul (PR). Biomas: Amazônia, Caatinga e Mata Atlântica.

Material examinado: BRASIL. Pernambuco: Mirandiba, 09/VI/2011, folhedo, Silva NA 242 (UFP 68470).

Comentários: espécie caracteristicamente Neotropical, onde tem registros em 14 países, $P$ nucleatum apresenta ampla distribuição no Brasil, ocorrendo em diferentes biomas. No semiárido nordestino, foi referida para o Piauí, Ceará e Pernambuco, em enclaves de cerrado e floresta úmida (Mobin \& Cavalcanti 1999; Alves \& Cavalcanti 1996; Alves et al. 2010). Na lista de espécies ocorrentes em brejos de altitude organizada por Costa (2005), foi citada para Pernambuco e Paraíba. O único espécime obtido no presente estudo foi coletado em Triunfo durante a estação seca, esporulando sobre serapilheira (Tab. 1-2).

10. Physarum rigidum (G. Lister) G. Lister, in Lister, Monogr. mycetozoa, ed. 336.1925

Esporângio gregário, 1,6 mm alt.; esporoteca discóide, amarela, 0,34 $\mathrm{mm}$ diâm; perídio membranáceo, simples, persistindo na base; pedicelo cilíndrico, castanho-enegrecido na base (0,37 $\mathrm{mm}$ larg.), mais claro no ápice $(0,05 \mathrm{~mm}$ larg.), 1,26 mm comp.; hipotalo membranáceo, inconspícuo, castanho-enegrecido; capilício formado por tubos achatados pouco ramificados contendo cálcio; esporada castanho claro; esporo globoso, verrucoso, castanho, 10,0-11,0 $\mu \mathrm{m}$ diâm.

Distribuição no Brasil: Norte (PA), Nordeste (PE e PI), Sudeste (SP). Biomas: Amazônia, Caatinga, Cerrado e Mata Atlântica.

Material examinado: BRASIL. Pernambuco: Triunfo, 19/I/2011, tronco morto caído, Silva NA 18 (UFP 68469).

Comentários: Physarum rigidum tem registros em oito países da região neotropical e está presente em quase todos os biomas brasileiros. Sua distribuição no país foi recentemente analisada por Parente et al. (2009), que efetuaram o primeiro registro de sua ocorrência em ambiente típico de caatinga, no Parque Estadual Serra da Capivara, Piauí. Esta espécie parece preferir ambientes úmidos e seu registro no presente estudo foi efetuado apenas no brejo de altitude, durante a estação chuvosa, quando um espécime foi coletado, esporulando sobre tronco em decomposição (Tab. 1-2). Esta é a primeira referência para o Sertão de Pernambuco e para brejo de altitude.

\section{Physarum stellatum (Massee) G.W. Martin, Mycologia 39(4): 461.1947}

Esporângio gregário, ereto ou inclinado, 1,65 mm alt.; esporoteca globosa, umbilicada na base, branca, 0,47 mm diâm.; perídio membranáceo, simples, persistindo na base, deiscência petaloide; hipotalo membranáceo, circular, castanho-enegrecido; pedicelo cilíndrico, sulcado, castanho-enegrecido na base $(0,13 \mathrm{~mm}$ larg. $)$ mais claro no ápice (0,08 mm larg.), 1,18 mm comp.; capilício delicado, ramificado, filamentos hialinos, nódulos de cálcio irregulares, brancos; pseudocolumela central, branca; esporada castanho escuro; esporo globoso, verrucoso, castanho claro, 9,0-10,0 $\mu \mathrm{m}$ diâm.

Distribuição no Brasil: Norte (AM e AP), Nordeste (AL, BA, CE, PE, PI, RN e SE), Sudeste (RJ e SP), Sul (PR). Biomas: Amazônia, Caatinga e Mata Atlântica.

Material examinado selecionado: BRASIL. Pernambuco: Triunfo, 19/I/2011, tronco morto caído, Silva NA 66 (UFP 68514).

Comentários: com ampla distribuição nos Neotrópicos e no Brasil, $P$. stellatum tem sido registrada tanto na Amazônia e Mata Atlântica como em enclaves de floresta úmida na Caatinga. Os cinco espécimes obtidos foram coletados sobre tronco em decomposição e folha, nas duas estações, todos restritos ao brejo de altitude de Triunfo (Tab. 1-2).

12. Physarum tenerum Rex, Proc. Acad. Nat. Sci. Philadelphia 42: 192. 1890

Esporângio gregário, pedicelado; esporoteca globosa, cinza; perídio membranoso, simples, castanho, persistente na base, deiscência petaloide; hipotalo membranáceo, castanho-enegrecido; pedicelo sulcado, cilíndrico, calcário, castanho escuro na base $(0,11 \mathrm{~mm}$ larg. $)$ clareando para o 
ápice (0,05 mm larg.), 1,2 mm comp.; capilício delicado, ramificado, hialino, nódulo de cálcio arredondado, branco; esporada castanho escuro; esporo globoso, verruculoso, castanho-violeta, 9,0-10,0 $\mu \mathrm{m}$ diâm.

Distribuição no Brasil: Norte (AM), Nordeste (BA, PE e SE), Sudeste (SP), Sul (RS). Biomas: Amazônia, Mata Atlântica e Caatinga.

Material examinado selecionado: BRASIL. Pernambuco: Triunfo, 08/VI/2011, tronco morto caído, Silva NA 217 (UFP 68464).

Comentários: com distribuição conhecida para 14 países dos Neotrópicos, P. tenerum é referida para quase todas as regiões e biomas do Brasil, embora não seja frequentemente coletada. $\mathrm{O}$ ambiente preferencial desta espécie parece ser a floresta úmida, porém Alves et al. (2010) a referem para o município de Graça, CE, em ambiente típico de Caatinga. Foi assinalada em Triunfo, com um espécime coletado na estação seca e outro na chuvosa, ambos sobre troncos em decomposição (Tab. 1-2).

\section{Reticulariaceae}

1. Dictydiaethalium plumbeum (Schumach.) Rostaf., in Lister, Monogr. mycetozoa, ed. 1 157. 1894

Pseudoetálio isolado, irregular, pulvinado, castanho, 1,7 mm alt. total, $11,3 \mathrm{~mm}$ larg.; perídio membranáceo, simples, castanho, delgado, deiscência apical; hipotalo irregular, membranáceo, castanho; pseudocapilício liso, castanho-amarelado, 4,0 $\mu \mathrm{m}$ diâm.; esporada castanho claro; esporo globoso, minutamente verrucoso, amarelo pálido, $9,0 \mu \mathrm{m}$ diâm.

Distribuição no Brasil: Nordeste (CE, PB e PE), Sudeste (SP e RJ). Biomas: Caatinga e Mata Atlântica.

Material examinado selecionado: BRASIL. Pernambuco: Triunfo, 31/III/2011, tronco morto caído, Silva NA 121 (UFP 68468).

Comentários: espécie cosmopolita, com registros em 12 países neotropicais, presente tanto em florestas úmidas como em vegetação típica de regiões áridas (Lado et al. 2003; Lado \& Basanta 2008; Estrada-Torres et al. 2009). Com raros registros no Brasil, desenvolve-se preferencialmente em ambientes úmidos, incluindo os que constituem enclaves florestais no bioma Caatinga, como referido por Cavalcanti \& Putzke (1998), Alves \& Cavalcanti (1996) e Alves et al. (2010) para o Ceará. O único espécime obtido foi coletado sobre tronco em decomposição, no brejo de altitude de Triunfo, no final da estação chuvosa (Tab. 1-2).

2. Reticularia jurana Meyl., Bull. Soc. Vaud. Sci. Nat. 44: 297. 1908

Etálio isolado, pulvinado, castanho, 0,08 mm larg., 0,01 $\mathrm{mm}$ alt. total; perídio simples, parcialmente persistente; hipotalo um pouco saliente fora do etálio, formando uma borda branca; pseudocapilício castanho claro, fino; esporada castanho-ferrugíneo; esporo globoso, reticulado em cerca de 2/3, castanho claro, 7,0 $\mu \mathrm{m}$ diâm.
Distribuição no Brasil: Nordeste (AL, PB, PE e SE), Sudeste (SP). Biomas: Caatinga e Mata Atlântica.

Material examinado: BRASIL. Pernambuco: Triunfo, 31/III/2011, tronco morto caído, Silva NA 113 (UFP 68465).

Comentários: cosmopolita, $R$. jurana tem registro em três das cinco regiões do Brasil, mas é raramente coletada. O único espécime obtido foi coletado em Triunfo, na estação chuvosa (Tab. 1).

\section{Lycogala epidendrum (L.) Fr., Syst. mycol. 3: 80. 1829}

Etálio subgloboso, agrupado, amarelo-pardo, $2,5 \mathrm{~mm}$ alt. $\times 3,5 \mathrm{~mm}$ diâm.; hipotalo inconspícuo; córtex persistente, deiscência apical; pseudocapilício ramificado, enrugado, margens não crenadas, 3,0-6,0 $\mu \mathrm{m}$ diâm.; esporada bege; esporo globoso, castanho claro a quase hialino, reticulado, 6,0-7,0 $\mu \mathrm{m}$ diâm.

Distribuição no Brasil: Norte (AM e RR), Nordeste (AL, BA, MA, PB, PE, RN e SE), Sudeste (RJ e SP), Sul (PR, RS e SC). Biomas: Amazônia, Caatinga e Mata Atlântica.

Material examinado selecionado: BRASIL. Pernambuco: Triunfo, 31/III/2011, tronco morto caído, Silva NA 117 (UFP 68513); ibidem; 19/I/2011, tronco morto caído, Silva NA 15 (UFP 68460).

Comentários: cosmopolita, com ampla distribuição nos Neotrópicos, L. epidendrum tem registros em diferentes ambientes vegetacionais, nas cinco regiões do Brasil. Quatro espécimes foram obtidos no brejo de altitude de Triunfo, durante a estação chuvosa, sobre tronco em decomposição (Tab. 1-2).

\section{Lycogala exiguum Morgan, J. Cincinnati Soc. Nat. Hist. 15(3-4): 134.1893}

Etálio subgloboso, agrupado, amarelo-pardo, 1,5 mm alt. $\times 2,5 \mathrm{~mm}$ diâm.; hipotalo inconspícuo, bege; córtex persistente, apresentando câmaras na face interna, deiscência apical; pseudocapilício ramificado, enrugado, 3,0-6,0 $\mu \mathrm{m}$ diâm.; esporada castanho-pardo; esporo globoso, castanho claro a hialino, reticulado, 6,0-7,0 $\mu \mathrm{m}$ diâm.

Distribuição no Brasil: Nordeste (AL, PB, PE, PI, RN e SE), Sudeste (SP), Sul (SC). Bioma: Mata Atlântica.

Material examinado selecionado: BRASIL. Pernambuco: Triunfo, 08/VI/2011, tronco morto caído, Silva NA 198 (UFP 68517).

Comentários: com ampla distribuição geográfica, $L$. exiguum é considerada por Lado \& Basanta (2008) como uma das espécies características da mixobiota neotropical. Ocorre em fragmentos de Floresta Atlântica e enclaves de Cerrado em seis dos nove estados do Nordeste, assim como do Sudeste (SP) e Sul (SC). No presente estudo, dois espécimes foram obtidos na estação chuvosa e um na estação seca, esporulando sobre tronco em decomposição, ambos no brejo de altitude de Triunfo (Tab. 1-2).

\section{Tubifera microsperma (Berk. \& M. A. Curtis) G.W. Martin, Mycologia 39 (4): 461. 1947 \\ Pseudoaetálio castanho, subgloboso, esporângios cilín- drico-angulares, 2,5-4,0 mm alt.; perídio simples, membra-}


noso, castanho claro, deiscência apical, persistente; hipotalo muito desenvolvido, cilíndrico, castanho-enegrecido, 2,5 a 4,0 mm comp.; esporada castanho; esporo globoso, reticulado, castanho claro, 6,0 $\mu \mathrm{m}$ diâm.

Distribuição no Brasil: Norte (AM, AP, PA e RR), Nordeste (AL, BA, CE, PB, PE, PI, RN e SE), Sudeste (SP), Sul (PR, RS e SC). Biomas: Amazônia, Caatinga e Mata Atlântica.

Material examinado: BRASIL. Pernambuco: Triunfo, 08/VI/2011, tronco morto caído, Silva NA 169 (UFP 68478).

Comentários: espécie considerada por Lado \& Basanta (2008) como característica da mixobiota neotropical, está representada em diferentes biomas brasileiros, com registros em brejos de altitude situados em Pernambuco e na Paraíba (Silva \& Cavalcanti 1988; Cavalcanti \& Brito Jr 1990). O único espécime obtido foi coletado em Triunfo, sobre tronco em decomposição, durante a estiagem (Tab. 1-2).

\section{Stemonitaceae}

1. Comatricha pulchella (C. Bab.) Rostaf., Sluzowce monogr. suppl. 27. 1876

Esporângio gregário, $1,12 \mathrm{~mm}$ alt.; esporoteca subcilíndrica, castanho, 0,66 mm comp.; perídio membranáceo, simples; pedicelo castanho escuro, subcilíndrico, $1 / 2$ da altura total, base $0,03 \mathrm{~mm}$, ápice $0,02 \mathrm{~mm}$; hipotalo membranáceo, castanho; columela subcilíndrica, castanho escuro, ramificando-se em toda sua extensão, atingindo até quase o ápice da esporoteca; capilício ramificado dicotomicamente, castanho claro; esporada castanho escuro; esporo espinuloso, castanho claro, $8,0 \mu \mathrm{m}$ diâm.

Distribuição no Brasil: Nordeste (BA, PB, PE, PI e SE), Sudeste (SP), Sul (SC). Biomas: Mata Atlântica e Caatinga.

Material examinado: BRASIL. Pernambuco: Triunfo, 08/VI/2011, córtex de árvore viva, Silva NA 236 (UFP 68509).

Comentários: Comatricha pulchella é referida para áreas áridas da Europa e da América do Norte (Novozhilov et al. 2006; Estrada-Torres et al. 2009), comportando-se preferencialmente como foliícola. Tem ampla distribuição nos Neotrópicos, ocorrendo em 10 países. No Brasil, foi registrada para as regiões Nordeste, Sul e Sudeste, mais comumente em florestas úmidas. Foi referida para áreas de caatinga arbustiva na Chapada Diamantina, BA (Gusmão et al. 2005) e para áreas de brejo de altitude na Paraíba (Costa 2005), não sendo relatada em áreas semelhantes no estado de Pernambuco. Um único espécime foi coletado no presente estudo, no brejo de altitude, sobre o córtex de árvore viva, na estiagem (Tab. 1-2).

2. Stemonitis axifera (Bull.) T. Macbr., N. Amer. Slime-moulds, ed. 1120.1899

Esporângio gregário, pedicelado, 3,17-3,36 mm alt.; esporoteca cilíndrica, castanho-ferrugínea, 1,55-1,84 mm; perídio membranáceo, simples; pedicelo cilíndrico a subcilíndrico, castanho, base 0,03 mm larg., ápice 0,02 mm e 1,68 mm comp.; columela subcilíndrica, castanho, ramificada até o ápice; hipotalo membranáceo, inconspícuo, castanho-enegrecido; capilício castanho-amarelado; esporada castanha; esporo globoso, castanho claro, apresentando poucas verrugas, quase liso, 4,5-7,0 $\mu \mathrm{m}$ diâm.

Distribuição no Brasil: Norte (AM e RR), Nordeste (AL, BA, CE, PB, PE, PI, RN e SE), Sudeste (MG, RJ e SP), Sul (PR e SC). Biomas: Amazônia, Mata Atlântica e Caatinga.

Material examinado selecionado: BRASIL. Pernambuco: Triunfo, 08/VI/2011, tronco morto caído, Silva NA 174 (UFP 68523).

Comentários: esta espécie possui ampla distribuição mundial, ocorrendo tanto em ambientes de florestas úmidas como florestas secas. O primeiro registro de $S$. axifera para o Brasil foi efetuado em 1896, para florestas úmidas de Santa Catarina (Cavalcanti \& Fortes 1995) e a primeira citação para o bioma Caatinga foi feita por Alves et al. (2010), que coletaram espécime em um enclave de floresta úmida no Ceará. No presente estudo, um exemplar foi encontrado sobre tronco em decomposição em área de caatinga na estação chuvosa e dois no brejo de altitude, em ambas as estações (Tab. 1-2).

3. Stemonitis fusca Roth, Bot. Mag. (Römer \& Usteri) 1(2): 26. 1787

Esporângio gregário, pedicelado, 5,0-8,36 mm alt. total; esporoteca subcilíndrica, castanho-enegrecido; pedicelo cilíndrico a subcilíndrico, castanho escuro, base $0,05 \mathrm{~mm}$ larg., ápice 0,03 mm larg. e 2,10-3,76 mm comp.; hipotalo membranáceo, castanho-enegrecido; capilício castanho, rede periférica espinescente com malhas $>3,0 \mu \mathrm{m}$, pontas livres no ápice; columela subcilíndrica, castanho escuro, ramificando-se até o ápice, 2,10-4,59 mm comp.; esporada castanho escuro; esporo globoso, verrucoso ou espinescente-reticulado, castanho escuro, 8,0-9,0 $\mu \mathrm{m}$ diâm.

Distribuição no Brasil: Norte (AM, PA e RR), Nordeste (AL, BA, PB, PE, PI, RN e SE), Sudeste (ES, RJ e SP), Sul (PR, RS e SC). Biomas: Amazônia e Mata Atlântica.

Material examinado selecionado: BRASIL. Pernambuco: Serra Talhada, 01/IV/2011, tronco morto caído, Silva NA 157 (UFP 68512).

Comentários: cosmopolita, S. fusca possui ampla distribuição no Brasil, comportando-se predominantemente como lignícola, em florestas úmidas da Amazônia e Mata Atlântica. Os dois exemplares obtidos no presente estudo foram coletados na estação seca, sobre tronco em decomposição em área de caatinga arbóreo-arbustiva (Tab. 1-2). Apesar de citada para regiões áridas de outros países (Estrada - Torres et al. 2009), a ocorrência de $S$. fusca ainda não havia sido registrada para vegetação típica de caatinga, embora tenha sido assinalada em brejo de altitude na $\mathrm{Pa}$ raíba (Costa 2005).

4. Stemonitis splendens Rostaf., Sluzowce monogr. 195. 1874

Esporângio gregário, pedicelado, $1,28 \mathrm{~mm}$ alt. total; esporoteca cilíndrica, castanho-enegrecido, 0,89 mm comp.; 
perídio membranáceo, evanescente; pedicelo castanho-enegrecido, cilíndrico, base $0,03 \mathrm{~mm}$, ápice $0,02 \mathrm{~mm}$ e 0,39 $\mathrm{mm}$ comp.; hipotalo membranáceo, castanho-enegrecido; columela cilíndrica, castanho-enegrecido, ramificada até o ápice; capilício castanho claro, rede periférica com malhas $>30,0 \mu \mathrm{m}$; esporada castanho-enegrecido; esporo globoso, castanho escuro, verrucoso 5,0-7,0 $\mu \mathrm{m}$ diâm.

Distribuição no Brasil: Norte (AM e PA), Nordeste (AL, BA, CE, PE, PI e SE), Sudeste (SP), Sul (PR, RS e SC). Biomas: Amazônia, Caatinga e Mata Atlântica.

Material examinado selecionado: BRASIL. Pernambuco: Triunfo, 08/VI/2011, tronco morto caído, Silva NA 174 (UFP 68523).

Comentários: espécie cosmopolita, com registros em 23 países dos Neotrópicos. No Brasil, foi assinalada pela primeira vez em florestas úmidas em Santa Catarina, no início do século passado (Cavalcanti \& Fortes 1995). Foi registrada em brejos de altitude da Paraíba e de Pernambuco, assim como em ambiente típico de caatinga, no Ceará (Costa 2005; Alves et al. 2010). O único espécime obtido no presente estudo foi coletado sobre tronco morto no brejo de altitude durante a estação chuvosa (Tab. 1-2).

5. Stemonitopsis subcaespitosa (Peck) Nann.-Bremek., Nederlandse Myxomyceten (Zutphen) 211. 1975

Esporângio pedicelado, $1,47 \mathrm{~mm}$ alt. total; esporoteca subcilíndrica, castanho; perídio membranáceo, simples, evanescente; pedicelo castanho, subcilíndrico, cerca de 1/3 do esporângio, base $0,05 \mathrm{~mm}$ larg., ápice 0,04 mm larg.; hipotalo membranáceo, irregular, castanho; columela subcilíndrica, castanho escuro, 1,07 mm alt.; capilício castanho claro, ramificado, malhas $<3,0 \mu \mathrm{m}$; esporada castanho; esporo globoso, castanho, liso, 7,0 $\mu \mathrm{m}$ diâm.

Distribuição no Brasil: Nordeste (AL e PE), Sul (RS). Bioma: Mata Atlântica.

Material examinado: BRASIL. Pernambuco: Mirandiba, 20/I/2011, tronco morto caído, Silva NA 95 (UFP 68525).

Comentários: Lado \& Basanta (2008) relatam a ocorrência desta espécie no México, Costa Rica, Argentina, Venezuela e Brasil, onde foi assinalada para fragmentos de Floresta Atlântica situados na região costeira de Pernambuco e Alagoas e no Rio Grande do Sul.

O único exemplar obtido no presente estudo, encontrado em área de caatinga arbustivo-arbórea na estação chuvosa, sobre tronco em decomposição (Tab. 1-2), constitui o primeiro registro para a Caatinga.

6. Stemonitopsis typhina (F.H. Wigg.) Nann.-Bremek., Nederlandse Myxomyceten (Zutphen) 209. 1975

Esporângio pedicelado, 2,9-3,3 mm alt. total; esporoteca cilíndrica a subcilíndrica, castanho, 1,45-1,90 mm comp.; perídio simples, membranoso, deiscência irregular, às vezes persistindo na base da esporoteca; pedicelo castanho-escuro, subcilíndrico, atingindo $1 / 2$ a $1 / 3$ da altura total do esporângio, base 0,05-0,04 mm larg., ápice
0,03-0,02 mm larg., às vezes apresentando uma bainha membranácea; hipotalo castanho-amarelado, circular, membranoso; capilício castanho-amarelado, delicado, formando uma rede periférica imperfeita; columela cilíndrica a subcilíndrica, castanho escuro, ramificada, bifurcada no ápice, 1,45- 1,10 mm comp.; esporada castanho; esporo verrucoso, com grupos de verrugas, globoso, castanho claro, 7,0-7,5 $\mu \mathrm{m}$ diâm.

Distribuição no Brasil: Norte (AM e RR), Nordeste (AL, CE, PB, PE e PI), Sudeste (SP), Sul (PR e RS). Biomas: Amazônia, Caatinga e Mata Atlântica.

Material examinado selecionado: BRASIL. Pernambuco: Triunfo, 08/VI/2011, tronco morto caído, Silva NA 201 (UFP 68511).

Comentários: com ampla distribuição nos Neotrópicos, S. typhina é citada para enclave de floresta úmida no semiárido cearense e em brejo de altitude na Paraíba. No presente estudo, dois espécimes foram coletados sobre troncos mortos caídos, na estação seca, ambos no brejo de altitude (Tab. 1-2).

\section{Trichiaceae}

1. Arcyria cinerea (Bull.) Pers., Syn. meth. fung. 1: 184.1801 Esporângio cilíndrico, gregário, cinza, 1,4-2,8 mm alt. total; perídio simples, persistente na base formando um calículo raso, membranáceo, hialino, face interna pontilhada; hipotalo castanho, membranoso, às vezes circular; pedicelo cilíndrico, castanho-enegrecido, base 0,13-0,16 mm larg., ápice 0,09-0,15 mm larg. e 0,5-1,3 mm compr., contendo cistos vesiculares, globosos, castanhos, $(10,0-18,0) 9,0-16,0 \mu \mathrm{m}$; capilício abundante, elástico, filamentos presos as bordas do calículo, amarelo claro a hialinos, bastante ramificados, 3,05,0 $\mu \mathrm{m}$ diam., espinulosos; esporada cinza; esporo globoso, amarelo claro a hialino, com espinhos diminutos a quase liso, 7,0-9,0 $\mu \mathrm{m}$ diâm.

Distribuição no Brasil: Norte (AC, AM, PA e RR), Nordeste (AL, BA, CE, PB, PE, PI, RN e SE), Sudeste (MG, RJ e SP), Sul (PR, RS e SC). Biomas: Amazônia, Caatinga, Cerrado e Mata Atlântica.

Material examinado selecionado: BRASIL. Pernambuco: Triunfo, 08/VI/2011, tronco morto caído, Silva NA 170 (UFP 68503); ibidem, Silva NA 187 (UFP 68504); ibidem, 31/III/2011, Silva NA 106 (UFP 68502); Serra Talhada, 10/ VI/2011, tronco morto caído, Silva NA 249 (UFP 68505).

Comentários: cosmopolita, A. cinerea é abundante e frequente em florestas úmidas tropicais, mas também ocorre em regiões áridas e semiáridas na América do Sul; na Europa, ocorre nas florestas temperadas e, embora rara, em locais de clima rigoroso como no sudeste da Sibéria, onde a pluviosidade anual é menor que $700 \mathrm{~mm}$ e a temperatura no inverno atinge $-45^{\circ} \mathrm{C}$ (Lado et al. 2007a; Kocheleva et al. 2008). No Brasil, ocorre em quase todos os biomas e regiões. No presente estudo, 20 espécimes foram coletados nas duas estações, sendo cinco em caatinga e 15 em brejo de altitude (Tab. 1). 
2. Arcyria denudata (L.) Wettst., Verh. Zool.-Bot. Ges. Wien 35: 535. 1886

Esporângio gregário, 4,7-5,4 mm alt. total; esporoteca cilíndrica, vermelha; perídio simples, membranoso, deiscência apical irregular, persistindo na base como um calículo em forma de funil ou mais raso, face interna reticulada; hipotalo castanho-enegrecido, membranoso, irregular, às vezes circular; pedicelo cilíndrico, castanho-enegrecido, base 0,13-0,21 mm larg., ápice 0,14-0,15 mm larg., 0,6-1,3 mm compr., contendo cistos ovoides, 8,0-(15,0)-13,0$(18,0) \mu \mathrm{m}$ diâm.; capilício abundante, elástico, vermelho claro, preso à borda do calículo, filamentos ramificados, ornamentados com dentes, anéis ou meio-anéis, 3,0-5,0 $\mu \mathrm{m}$ diâm.; esporada vermelha; esporo vermelho claro quase hialino, globoso, com verrugas esparsas, 7,0-8,0 $\mu \mathrm{m}$ diâm.

Distribuição no Brasil: Norte (AM, RO e RR), Nordeste (BA, CE, PB, PE e PI), Sudeste (RJ e SP) e Sul (PR, RS e SC). Biomas: Amazônia, Caatinga, Cerrado e Mata Atlântica.

Material examinado selecionado: BRASIL. Pernambuco: Triunfo, 31/III/2011, tronco morto caído, Silva NA 116 (UFP 68501); ibidem, 08/VI/2011, tronco morto caído, Silva NA 208 (UFP 68497); ibidem, Silva NA 182 (UFP 68499); 08/VI/2011, tronco morto caído, Silva NA 208 (UFP 68497); ibidem, Serra Talhada, 08/VI/2011, tronco morto caído, Silva NA 252 (UFP 68498); ibidem, 10/VI/2011, Silva NA 261 (UFP 68500).

Comentários: cosmopolita, $A$. denudata é uma das espécies mais características de florestas úmidas neotropicais, onde forma extensas frutificações, sendo comum em troncos caídos. Tem ampla distribuição no Brasil, com registros para quase todos os biomas, incluindo a Caatinga.

Apesar de se enquadrar entre as espécies com melhor representatividade no total de espécimes obtidos, $A$. denudata foi registrada apenas em Triunfo, na estação seca (10 espécimes) e na chuvosa (seis espécimes), comportando-se como lignícola (Tab. 1-2).

\section{Hemitrichia calyculata (Speg.) M.L. Farr, Mycologia 66(5): 887. 1974}

Esporângio gregário ou disperso, 1,4-2,6 mm alt. total; esporoteca piriforme, castanho-amarelado; perídio simples, membranoso, amarelo, persistindo na base como um calículo fundo, com ou sem bordas revolutas; hipotalo membranáceo, irregular, castanho-enegrecido; pedicelo castanho-enegrecido, cilíndrico, base 0,11-0,21 mm larg., ápice 0,08-0,16 mm larg., 0,7-1,3 $\mathrm{mm}$ comp., com cistos semelhantes a esporos; capilício amarelo, abundante, elástico, preso no centro do calículo, filamentos 5,0-6,0 $\mu \mathrm{m}$ diâm., ramificados, ornamentados com bandas espiraladas, com poucas pontas livres; esporada amarela; esporo amarelo claro, globoso, verrucoso, 8,0 $\mu \mathrm{m}$ diâm.

Distribuição no Brasil: Norte (AM e RR), Nordeste (AL, BA, CE, MA, PB, PE, PI, RN e SE), Centro-Oeste (DF), Sudeste (RJ e SP), Sul (RS e SC). Biomas: Amazônia, Caatinga, Cerrado e Mata Atlântica.
Material examinado selecionado: BRASIL. Pernambuco: Triunfo, 19/I/2011, tronco morto caído, Silva NA 92 (UFP 68508); ibidem, 31/III/2011, Silva NA 115 (UFP 68506); ibidem, Silva NA 120 (UFP 68507).

Comentários: generalista, podendo ocupar diferentes microhabitats e ecossistemas de regiões temperadas e tropicais, $H$. calyculata tem ampla distribuição no mundo e no Brasil, onde está presente em todas as regiões e em quase todos os biomas (Bezerra et al. 2009).

Hemitrichia calyculata foi a espécie mais característica da mixobiota do brejo de altitude (56 espécimes), ocorrendo também no ambiente de caatinga de Serra Talhada (quatro espécimes), esporulando nas estações seca e chuvosa, ora em frutificações escassas (dois a cinco esporocarpos), ora abundantes (Tab. 1-2).

\section{Hemitrichia serpula (Scop.) Rostaf. ex Lister, Monogr.} mycetozoa, ed. 1: 179. 1894

Plasmodiocarpo reticulado, amarelo-alaranjado, 0,58 a 0,71 mm extensão; perídio simples, membranoso, brilhante, deiscência apical irregular, persistente na base; capilício elástico, abundante, filamentos 5,0-7,0 $\mu \mathrm{m}$ diâm., amarelo-alaranjado, com 3-4 bandas espiraladas e espinhos; esporada amarelo gema de ovo; esporo amarelo claro, globoso, com bandas reticuladas por bordas, 8,0-13,0 $\mu \mathrm{m}$ diâm.

Distribuição no Brasil: Norte (AM, AP, PA e RR), Nordeste (AL, BA, CE, PB, PE, PI e SE), Centro-Oeste (DF e MT), Sudeste (RJ e SP), Sul (PR, RS e SC). Biomas: Amazônia, Caatinga, Cerrado e Mata Atlântica.

Material examinado selecionado: BRASIL. Pernambuco: Serra Talhada, 10/VI/2011, tronco morto caído, Silva NA 243 (UFP 68443); ibidem, Silva NA 244 (UFP 68444); ibidem, Silva NA 250 (UFP 68445).

Comentários: cosmopolita, $H$. serpula ocupa diferentes microhabitats, sendo registrada tanto em florestas úmidas tropicais quanto em desertos da América do Norte e do Sul ou na região árida e fria da Sibéria (Lado et al. 2007a; Kosheleva et al. 2008). No Brasil, é encontrada em todas as regiões e biomas onde foram efetuados estudos sobre mixomicetos, incluindo a Caatinga (Bezerra et al. 2009). No presente estudo, foi registrada nos ambientes de caatinga (quatro espécimes) e brejo de altitude (nove espécimes) mas não se mostrou frequente na mixobiota local (Tab. 1-2).

\section{Comparação das mixobiotas}

As três subclasses de mixomicetos estão representadas nas áreas estudadas, com quatro famílias, quatro gêneros e quatro espécies na caatinga arbustivo-arbórea de Mirandiba $\left(\mathrm{S} / \mathrm{G}_{\mathrm{M}}=1,0\right)$, seis famílias, nove gêneros e 12 espécies ( $\mathrm{S} /$ $\left.\mathrm{G}_{\mathrm{ST}}=1,3\right)$ na caatinga arbóreo-arbustiva de Serra Talhada e sete famílias, 14 gêneros e 30 espécies $\left(S / G_{T}=2,14\right)$ na floresta úmida de Triunfo (Tab. 1). Assim, embora os mixomicetos sejam mais abundantes no brejo de altitude, onde a pluviosidade anual é praticamente o dobro da registrada nas duas áreas de caatinga, a mixobiota nelas presente é 
mais diversificada quando se considera a relação espécie/ gênero; estes valores são semelhantes aos encontrados por Ferreira \& Cavalcanti (2011) para Mirandiba e Serra Talhada $(0,63-1,5)$ e encaixam-se na faixa 1,4-2,1 referida para regiões de alta latitude norte e sul; o valor encontrado para o brejo de altitude, embora um pouco mais elevado, difere da faixa 2,2-4,6 referida para florestas temperadas e tropicais (Basanta et al. 2010; Cavalcanti \& Mobin 2004).

Duas das quatro espécies assinaladas na caatinga arbustivo-arbórea de Mirandiba também estão presentes na caatinga arbóreo-arbustiva de Serra Talhada $\left(\mathrm{CC}_{\mathrm{M} / \mathrm{ST}}=\right.$ 0,25 ) enquanto apenas uma delas, $C$. fruticulosa, também ocorre na floresta úmida de Triunfo $\left(\mathrm{CC}_{\mathrm{M} / \mathrm{T}}=0,06\right)$. Apesar da mixobiota da caatinga de Serra Talhada não se assemelhar à de Triunfo $\left(\mathrm{CC}_{\mathrm{ST} / \mathrm{T}}=0,39\right)$ compartilha mais espécies que com a caatinga de Mirandiba.

Nesta pequena fração da diversidade total da mixobiota da Caatinga ocorrem espécies raramente coletadas, embora apresentem ampla distribuição mundial, como F. megaspora, com apenas um registro no Sudeste do país (Cavalcanti 2012) e D. perforatum, ainda não assinalada no Brasil.

Mais da metade (67\%) das espécies podem ser consideradas raras na mixobiota local, representadas apenas por um ou dois espécimes (Tab. 1). Merece destaque a abundância das Trichiaceae, que juntas correspondem a $53 \%$ do total de espécimes obtidos. Hemitrichia foi o gênero mais comumente coletado (73 espécimes), principalmente no brejo de altitude, embora representado por apenas duas espécies (Tab. 1).

Os dados obtidos evidenciam que as ilhas de floresta úmida existentes na Caatinga, regionalmente conhecidas como brejos de altitude, abrigam uma mixobiota distinta da encontrada em áreas próximas cobertas pela vegetação típica do bioma. Os resultados também sugerem que o padrão de distribuição dos mixomicetos na Caatinga sofre a influência da disponibilidade de substratos e microhabitats decorrentes das diferenças de altitude e pluviosidade.

\section{Agradecimentos}

Os autores agradecem o apoio financeiro da FACEPE e do CNPq (proc.305967/2009-6) bem como o auxílio da equipe do LABMIX-UFPE nos trabalhos de campo e laboratório, especialmente à MSc Antônia Aurelice A. Costa e ao MSc. Leandro A. N. N. Agra.

\section{Referências bibliográficas}

Agra, L.A.N.N.; Lemos, D.B.N.; Powell, N.V.; Medrado, W.T. \& Cavalcanti, L.H.C. 2010. Occurrence of Lycogala epidendrum (Myxomycetes) in a mangrove environment in Brazil. Revista brasileira de Biociência 8(2): 164-168.

Alcoforado-Filho, F.G.; Sampaio, E.V.S.B. \& Rodal, M.J.N. 2003. Florística e fitossociologia de um remanescente de vegetação caducifólia espinhosa arbórea em Caruaru, Pernambuco. Acta Botanica Brasilica 17(2): 287-303
Alves, M.H. \& Cavalcanti, L.H. 1996. Myxomycetes em palmeiras (Arecaceae). Acta Botanica Brasilica 10(1): 1-7.

Alves, M.; Araujo, M.F.; Maciel, J.R. \& Martins, S. (Orgs.). 2009. Flora de Mirandiba. Recife, Associação Plantas do Nordeste.

Alves, M.H.; Costa, A.A.A. \& Cavalcanti, L.H. 2010. Myxomycetes, state of Ceará, northeastern Brazil. Check List 6(4): 555-558.

Basanta, D.W.; Lado, C.; Estrada-Torres, A. \& Stephenson, S.L. 2010. Biodiversity of myxomycetes in subantarctic forests of Patagonia and Tierra del Fuego, Argentina. Nova Hedwigia 90: 45-79.

Bates, S. T. \& Barber, A. 2008. A preliminary checklist of Arizona slime molds. Canotia 4(1): 8-19.

Bezerra, M.F.A.; Bezerra, A.C.C.; Nunes, A.T.; Lado, C. \& Cavalcanti, L.H 2008. Mixobiota do Parque Nacional Serra de Itabaiana, Sergipe, Brasil: Physarales. Acta Botanica Brasilica 22(4): 1044-1056.

Bezerra, A.C.C.; Cavalcanti, L.H. \& Dianese, J.C. 2009. Species of Hemitrichia (Trichiaceae, Myxomycetes) in Brazil. Mycotaxon 107: 35-48.

Blackwell, M. \& Gilbertson, R. L. 1980. Sonoran desert myxomycetes. Mycotaxon 11(1): 139-149.

Cavalcanti, L.H. 2012. Myxomycota. In: Lista de espécies da Flora do Brasil. Jardim Botânico do Rio de Janeiro. http://floradobrasil.jbrj. gov.br/2012. (Acesso em 12/02/1012).

Cavalcanti, L.H. \& Brito Júnior, S.C. 1990. Enteridiaceae do Brasil. Biologica Brasilica 2(2): 241-260.

Cavalcanti, L.H.; Bezerra, A.C.C.; Costa, A.A.A.; Ferreira I.N. \& Bezerra, M.F.A. 2008. Occurrence and distribution of the Ceratiomyxales (Myxomycetes) in Northeastern Brazil. Brazilian Archives of Biology and Technology 51(5): 971-980.

Cavalcanti, L.H.; Bezerra, A.C.C.; Costa, A.A.A.; Nascimento, I.F. \& Bezerra, M.F. 2009. Distribution of Diachea (Didymiaceae, Myxomycetes) in the northeastern region of Brazil. Mycotaxon 110: 163-172.

Cavalcanti, L.H. \& Fortes, S.T. 1995. Myxomycetes do Estado de Santa Catarina (Brasil). Boletim da Sociedade Broteriana 67: 23-35.

Cavalcanti, L.H. \& Mobin, M. 2004. Myxomycetes associated with palm trees at the Sete Cidades National Park, Piauí State, Brazil. Systematics and Geography of Plants 74: 109-127.

Cavalcanti, L.H. \& Putzke, J. 1998. Myxomycetes da Chapada do Araripe - CE, Brasil. Acta Botanica Brasilica 12(3): 253-261.

Cavalcanti, L.H.; Souza, W.P.; Santos, D.S. \& Góes-Neto, A. 2006. Filo Myxomycota. Pp. 49-74. In: Gusmão, L.F.P. \& Maia, L.C. (Orgs.). Diversidade e caracterização dos fungos do semiárido brasileiro. Recife, Associação de Plantas do Nordeste.

Costa, A.A.A. 2005. Riqueza e diversidade de Myxomycetes em Floresta Atlântica: brejo de altitude da Mata do Pau-Ferro (Areia, Paraíba, Brasil). Dissertação de Mestrado, Universidade Federal de Pernambuco, Recife.

Costa, A.A.A.; Tenório, J.C.G.; Ferreira, I.F. \& Cavalcanti, L.H. 2009. Myxomycetes de Floresta Atlântica: novas referências de Trichiales, Liceales e Stemonitales para o Estado da Paraíba, Nordeste do Brasil. Acta Botanica Brasilica 23(2): 313-322.

Costa, A.A.A.; Ferreira, I.N.; Bezerra, M.F.A. \& Cavalcanti, L.H. 2011. Mixobiota de Floresta Atlântica: novas referências de Physarales para o estado da Paraíba, Nordeste do Brasil. Revista Brasileira de Botanica 34(2): 177-185.

Estrada-Torres, A.; Basanta, D.W.; Conde, E. \& Lado, C. 2009. Myxomycetes associated with dryland ecosystems of the Tehuacán-Cuicatlán Valley Biosphere Reserve, Mexico. Fungal Diversity 36: 17-56.

Farr, M.L. 1976. Myxomycetes. Flora Neotropica. Mon. 16. New York, The New York Botanical Garden.

Fenouil, T. 2004. Découverte d'un myxomycète nouveau pour l'Europe, Physarum echinosporum Lister. Bulletin Semestriel de la Fédérations des Associations Mycologiques Mediterranéennes 26: 41-44.

Ferraz E.M.N.; Rodal, M.J.N.; Sampaio, E.V.S.B. \& Pereira, R.C.A. 1998 Composição florística em trechos de vegetação de caatinga e brejo de altitude na região do Vale do Pajeú, Pernambuco. Revista Brasileira de Botânica 21(1): 7-15.

Ferreira, I.N. \& Cavalcanti, L.H. 2011. Myxomycetes associados a cactáceas no agreste e sertão de Pernambuco, Brasil. Biotemas 24(2): 1-11.

Góes-Neto, A. \& Cavalcanti, L.H. 2002. Myxomycetes of the state of Bahia, Brazil: historical review and current situation. Mycotaxon 82: 335-342. 
Gottsberger, G. 1968. Myxomycetes aus Bahia und Goiás. Nova Hedwigia 15: 361-368.

Gusmão, L.F.P.; Góes-Neto, A. \& Cruz, A.C.R. 2005. Fungos. Pp. 225242. In: Juncá, F.A.; Funch, L. \& Rocha, W. (Orgs.). Biodiversidade e Conservação da Chapada Diamantina. Brasília, Ministério do Meio Ambiente.

Hochgesand, E. \& Gottsberger, G. 1996. Myxomycetes from the state of São Paulo, Brazil. Boletim do Instituto de Botânica 10: 1-46.

Keller, H.W. \& Schoknecht, J.D. 1989. Fuligo megaspora, a Myxomycete with unique spore ornamentation. Mycologia 81(3): 454-458.

Kosheleva, A.P.; Novozhilov, Y.K. \& Schnittler, M. 2008. Myxomycete diversity of the State reserve "Stolby" (southeastern Siberia, Russia): a preliminary report. Fungal Diversity 31: 45-62.

Lado, C. \& Basanta, W.D. 2008. A Review of Neotropical Myxomycetes (1828-2008). Anales Jardin Botanico de Madrid 65(2): 211-254.

Lado, C.; Basanta, D.W.; Estrada-Torres, A.; Carvajal, E.G.; Aguilar, M. \& Hernández-Crespo, J.C. 2009. Description of a new species of Perichaena (Myxomycetes) from arid areas of Argentina. Anales Jardin Botanico de Madrid 66: 63-70.

Lado, C.; Estrada-Torres, A. \& Stephenson S.L. 2007a. Myxomycetes collected in the first phase of a north-south transect of Chile. Fungal Diversity 25: 81-101.

Lado, C.; Estrada-Torres, A.; Stephenson, S.L.; Basanta, D.W. \& Schnittler, M. 2003. Biodiversity assessment of myxomycetes from two tropical forest reserves in Mexico. Fungal Diversity 12: 67-110.

Lado, C.; Mosquera, J.; Estrada-Torres, A.; Beltrán-Tejera, E. \& Basanta, D.W. 2007b. Description and culture of a new succulenticolous $D i$ dymium (Myxomycetes). Mycologia 99(4): 602-611.

Leal, I.R.; Tabarelli, M. \& Silva, J.M.C. da. 2003. Ecologia e conservação da caatinga. Recife, Universidade Federal de Pernambuco.

Lister, A. 1925. A monograph of the Mycetozoa. $3^{\text {a }}$ ed. London, British Museum of Natural History.

Martin, G.W. \& Alexopoulos, C.J. 1969. The Myxomycetes. Iowa, University of Iowa Press.
Mobin, M. \& Cavalcanti, L.H. 1999. Physarales (Myxomycetes) do Parque Nacional de Sete Cidades, Piauí, Brasil. Hoehnea 26(1): 1-14.

Ndiritu, G.; Winsett, K.E.; Spiegel, F.W. \& Stephenson, S.L. 2009. A checklist of African myxomycetes. Mycotaxon 107: 353-356.

Novozhilov, Y. K.; Mitchell, D. W. \& Schnittler, M. 2003.Myxomycete biodiversity of the Colorado Plateau. Mycological Progress 2:243-258.

Novozhilov, Y.K.; Schnittler, M.; Anastasia, V.V. \& Konstantin, A.F. 2010. Myxomycete diversity of the Altay Mountains (southwestern Siberia, Russia). Mycotaxon 111(2): 91-94.

Novozhilov, Y.K.; Zemlyanskaya, I.V.; Schnittler, M. \& Stephenson, S.L. 2006. Myxomycete diversity and ecology in the arid regions of the Lower Volga River Basin (Russia). Fungal Diversity 23: 193-241.

Novozhilov, Y.K.; Zemlyanskaya, I.V.; Schnittler, M. \& Stephenson, S.L. 2008. Two new species of Perichaena (Myxomycetes) from arid areas of Russia and Kazakhstan. Mycologia 100(5): 816-822.

Parente, M.P.M.; Bezerra, M.F.A. \& Cavalcanti L.H. 2009. Myxomycetes, Physarales, Physaraceae, Physarum rigidum (G. Lister) G. Lister: Distribution extension and new records. Check List 5(4): 759-762.

Poulain, M.; Meyer, M. \& Bozonnet, J. 2011. Les Myxomycètes. Sévrier, Fédération Mycologique et Botanic Dauphiné-Savoie.

Rojas, C.; Schnittler, M.; Biffi, D. \& Stephenson, S.L. 2008. Microhabitat and niche separation in species of Ceratiomyxa. Mycologia 100(6): 843-850.

Santos, E.J. \& Cavalcanti L.H. 1991. Myxomycetes do Canavial I. Levantamento florístico em Carpina, Pernambuco. Acta Botanica Brasilica 5: 53-61.

Silva, M.I.L. \& Cavalcanti, L.H. 1988. Myxomycetes ocorrentes nos brejos de Pernambuco. Boletim Micológico 4(1): 31-35.

Stephenson, S.L.; Schnittler, M.; Lado, C.; Estrada-Torres, A.; Basanta, W.D.; Landolt, J.; Novozhilov, Y.K.; Clark, J.; Moore, D. \& Spiegel, F. 2004. Studies of neotropical mycetozoans. Systematics and Geography of Plants 74: 87-108. 